\title{
Groundwater Pathway Mapping Using Electrical Resistivity Tomography (ERT) Method
}

\author{
Syazwan Aiman Sufiyanussuari ${ }^{1}$, Saiful Azhar Ahmad Tajudin ${ }^{1,4 *}$, Mohammad \\ Izzat Shaffiq Azmi ${ }^{1}$, Muhammad Nur Hidayat Zahari ${ }^{2,4}$, Nordiana Mohd \\ Muztaza $^{3}$
}

${ }^{1}$ Faculty of Civil and Built Environment,

Universiti Tun Hussein Onn Malaysia, 86400 Johor, MALAYSIA

${ }^{2}$ Faculty of Electrical and Electronic,

Universiti Tun Hussein Onn Malaysia, 86400 Parit Raja, Johor, MALAYSIA

${ }^{3}$ School of Physics, Universiti Sains Malaysia, 11800 USM, Penang, MALAYSIA

${ }^{4}$ Preston GeoCEM Sdn Bhd, 33A, Jalan Universiti 4, Taman Universiti, 86400 Parit Raja, Johor, MALAYSIA

*Corressponding Author

DOI: https://doi.org/10.30880/jsue.2021.01.01.005

Received 24 August 2021; Accepted 11 October 2021; Available online 16 December 2021

\begin{abstract}
Geophysical electrical resistivity method has been one of the more popular non-destructive method to explore the subsurface. Geophysical electrical resistivity tomography (ERT) subsurface profiling was conducted to map the groundwater path along the embankment. The groundwater path able to decrease the slope stability, thus its need to locate the position for conduct the slope remediation via subsoil drainage. In this study, Terrameter LS2 model, electrodes, cables, battery, and cable connectors were the equipment used for measurement. This study uses cable spread line at $200 \mathrm{~m}$ with $2.5 \mathrm{~m}$ spacing between electrodes by using gradient protocol. The resistivity data was analyzed using RES2DINV software. The interpretation of groundwater path is based on the resistivity values less than 100 ohm.m, which is interpreted as saturated materials. This study demonstrates the efficiency of application of electrical resistivity tomography (ERT) in detecting the groundwater pathways. This investigation will help in sustaining the slope stability via indicating the position of groundwater pathways, and thus implementing the slope remediation work.
\end{abstract}

Keywords: Groundwater, electrical resistivity tomography, slope instability

\section{Introduction}

The groundwater pathway is unpredictable and can generate the pore water pressure which may cause slope instability and ground subsidence due to the weakening of soil shear strength. The groundwater movement is mainly controlled by the porosity and permeability of the underlying soil [1-3]. Therefore, it is important to locate the groundwater pathway in order to mitigate future potential failure. Over the years, electrical resistivity tomography (ERT) has become one of the principal techniques extensively used in groundwater exploration. This technique has demonstrated its reliability in the characterization of potential water underneath the earth via showing the 2-dimensional ERT of subsurface. The ERT method is conducted by injecting direct current to the ground and measuring the resistivity of the material. The electrical resistivity value is highly influenced by the water content of the ground as stated by the Archie's law. Therefore, ERT method is appropriate to be used in order to differentiate between wet and 
dry soil. As a result, the electrical resistivity tomography investigation is able to delineate the areas of groundwater underneath the slope [4-9]. This paper intends to map the groundwater pathway by using ERT method.

\section{Methodology and Instrumentation}

ERT is a non-destructive subsurface exploration technique which has been widely applied especially in hydrogeology, geological, environmental and engineering problems [10-12]. This technique was applied in the earth slope to acquire a comprehensive image of the subsurface to characterize the pathway of the groundwater. For this purpose, three resistivity survey lines were laid-out at 200 meters length using four multipurpose cables with spacing of 2.5-meter electrodes from top to the toe of the slope as shown in Fig. 1. The survey lines are referred as RL1, RL2 and RL3. The gap between the survey resistivity lines were 155-meter apart. From visual inspection it was observed the water seepage occurred at toe slope at berm \# 5 as shown in Fig.2.

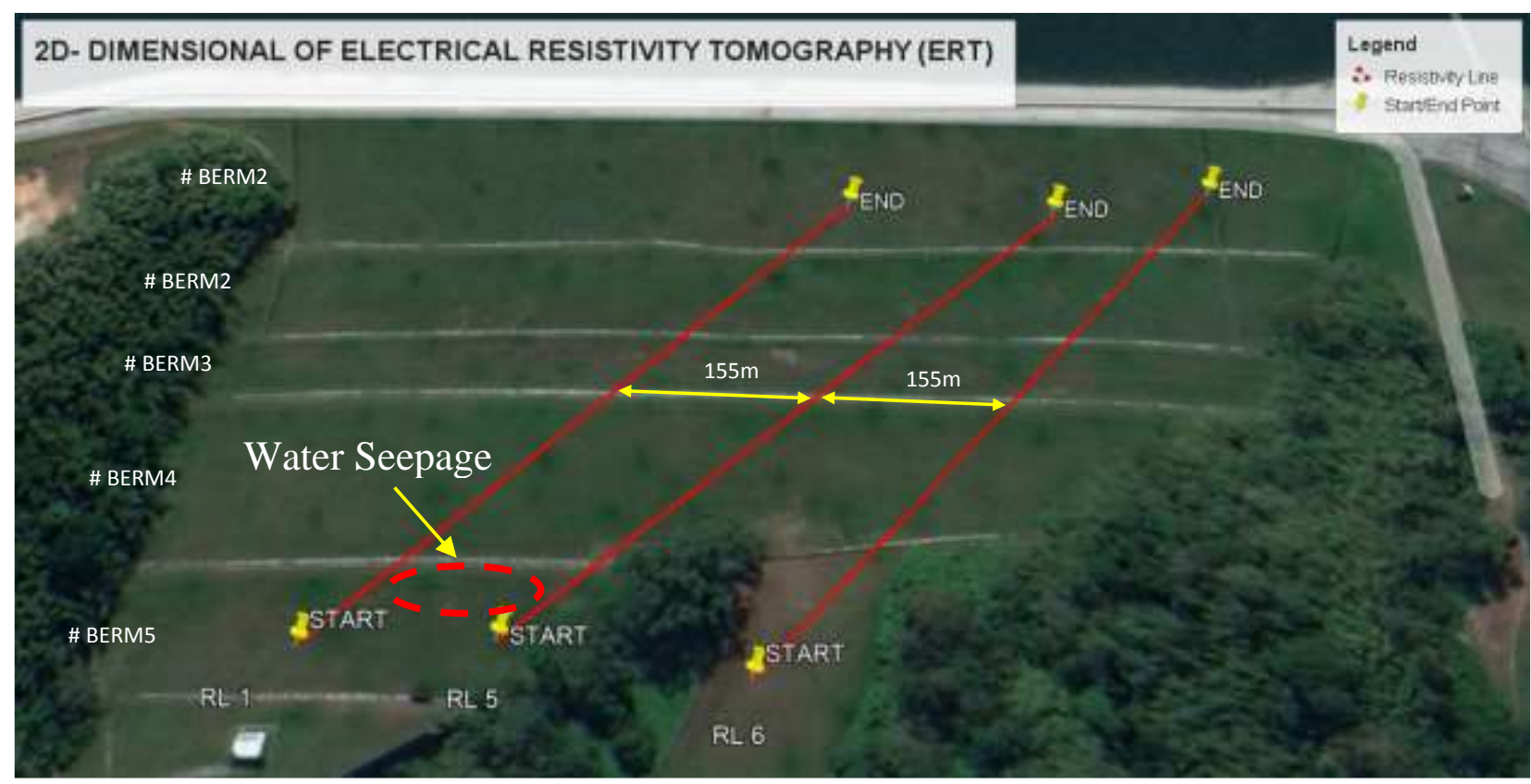

Fig. 1 - Resistivity lines laid on the slope
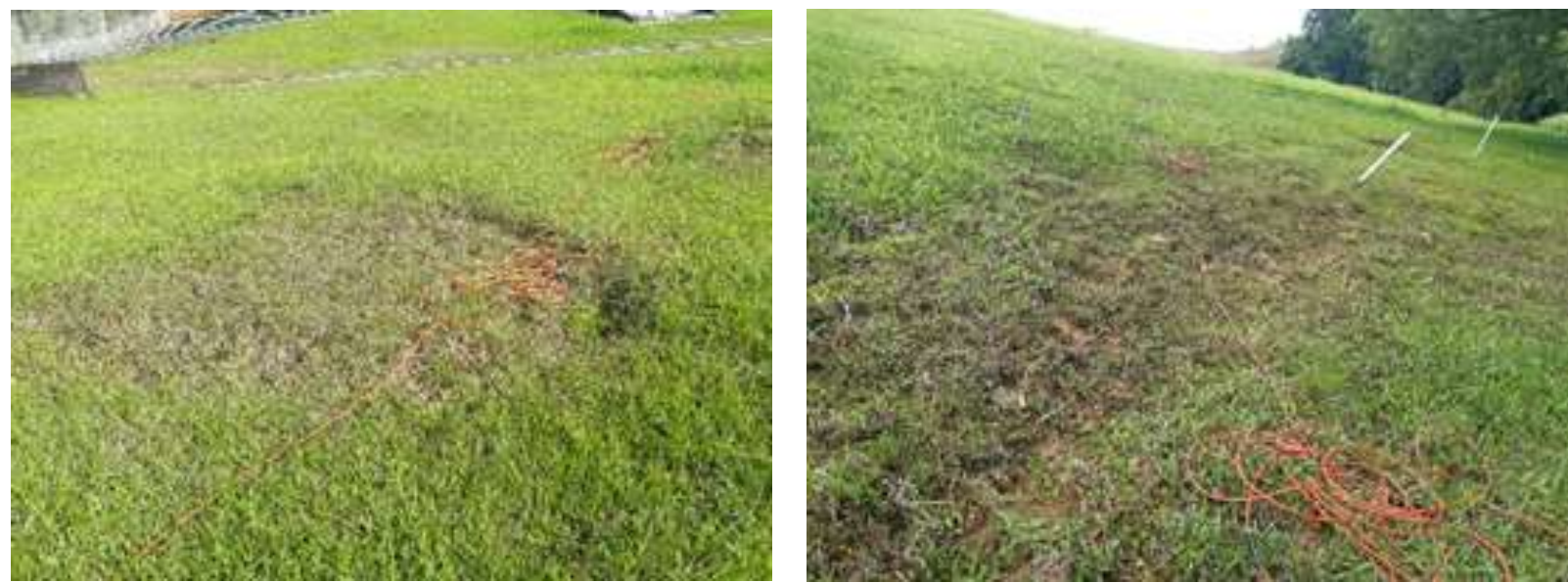

Fig. 2 - Water seepage occurred at \#Berm 5

The apparent resistivity is automatically stored for further processing using RES2DINV program to gives a tomography contour model in two dimensions [13]. The processes and results were expressed in the form of subsurface imaging model. The theory is based on soil electrical resistivity which use numerous numbers of electrodes positioned along the profile or at the research area. ERT was carried out using ABEM Terrameter LS2 with gradient method of electrode arrays that measures depth coverage up to 40-meters below the central part of the profile and decreases with distance away from the center building in a pseudo section of electrical resistivity imaging. Several equipment which includes 4 units of multi-purpose cable, 64 units of jumper cable, 61 units of stainless-steel electrode, 2 units of cable 
connector, and 1 unit of 12-volt battery. The profile lines were measured from distance between first electrode position, sharing electrode position, center of Terrameter LS2, and last electrode position according to specified profile length as shown in Table 1 to identify the location to putting out electrode cables. The electrode cable arrangement is shown in Fig.3.

Table 1 - Electrode cable distance according to profiles lines length

\begin{tabular}{|c|c|c|c|c|}
\hline $\begin{array}{c}\text { Profile } \\
\text { Length }(\mathbf{m})\end{array}$ & $\begin{array}{l}\text { C 1/ Initial electrode } \\
\text { - C1/C2 (sharing) }\end{array}$ & $\begin{array}{l}\text { C1/C2 (sharing) - } \\
\text { C2/C3 (Center) }\end{array}$ & $\begin{array}{c}\text { C2/C3 (Center) - } \\
\text { C3/C4 (sharing) }\end{array}$ & $\begin{array}{l}\text { C3/C4 (sharing) - } \\
\text { C4 / Last electrode }\end{array}$ \\
\hline $200 \mathrm{~m}$ & $50 \mathrm{~m}$ & $50 \mathrm{~m}$ & $50 \mathrm{~m}$ & $50 \mathrm{~m}$ \\
\hline \multicolumn{5}{|l|}{ • } \\
\hline $\begin{array}{l}\mathrm{C} 1 / \text { Initial } \\
\text { Electrode }\end{array}$ & $\mathrm{Cl} / \mathrm{C} 2$ & & C? & $\begin{array}{l}\text { C1/Final } \\
\text { Electrode }\end{array}$ \\
\hline & & 22 & able 3 & Cable 4 \\
\hline
\end{tabular}

Fig. 3 - Electrode cable arrangement

\subsection{Interpretation Technique}

The resistivity method basically measures the resistivity distribution of the subsurface material. Table 2 shows the resistivity value of some of the typical rocks, soil materials and water [14]. The resistivity igneous and metamorphic rocks are mainly dependent on the degree of fracturing since these type of rock typically have high resistivity values. Shallow water table are generally found in Malaysia where the groundwater will ocassionally filled the rock fractures. Therefore, the low resistivity values were affected by a large fractured on the rocks. For instances, the resistivity of limestones varies from saturated to dry condition with $50 \mathrm{ohm}-\mathrm{m}$ to $4000 \mathrm{ohm}-\mathrm{m}$, respectively. The resistivity values of groundwater saturated rocks varies from a few ohm-m to a less than a hundred ohm-m and differ from low to moderate resistivity. The resistivity values are low to moderate when these rocks are saturated with groundwater, from a few ohm-m to a less than one hundred ohm-m. Soils above the water table are more dry and have a higher resistivity value of several hundred to several thousand ohm-m, whereas soils below the water table are usually less than $100 \mathrm{ohm}-\mathrm{m}$ resistivity values. Apart from that, clay has a much lower resistivity than sand. Table 3 shows some of the resistivity value that had been used in interpretation and analysis result.

Table 2 - Resistivity of some common rocks and soil materials in the survey area [14]

\begin{tabular}{cc}
\hline Material & Resistivity $(\mathbf{O h m} . \mathbf{m})$ \\
\hline Alluvium & 10 to 800 \\
Sand & 60 to 1000 \\
Clay & 1 to 100 \\
Groundwater (fresh) & 10 to 100 \\
Sandstone & $8-4 \times 10^{3}$ \\
Shale & $20-2 \times 10^{3}$ \\
Limestone & $50-4 \times 10^{3}$ \\
Granite & 5000 to $1,000,000$ \\
\hline
\end{tabular}

Table 3 - Electrical resistivity of some types of waters [14]

\begin{tabular}{cc}
\hline Type of water & Resistivity (Ohm.m) \\
\hline Precipitation & 30 to 1000 \\
Surface water, in areas of igneous rock & 30 to 500 \\
Surface water, in areas of sedimentary rock & 10 to 100 \\
Groundwater, in areas of igneous rock & 30 to 150 \\
Groundwater, in areas of sedimentary rock & $>1$ \\
Seawater & $\approx 0.2$ \\
Drinking water (max. salt content $0.25 \%)$ & $>1.8$ \\
Water for irrigation and stock watering (max. salt content $0.25 \%)$ & $>0.65$ \\
\hline
\end{tabular}


The result of Electrical Resistivity Tomography (ERT) is discussed according either from west to east or north to south zone. The interpretation uses low resistivity value below $100 \mathrm{Ohm} . \mathrm{m}$ are interpreted as a water zone either in soil or rock of igneous formation. This subsurface water causes the surrounding soil and rock are saturated. Table 4 shows the interpretation of groundwater resistivity in igneous rock [15]. The data was processed via removed negative data and bad data points and inverted to measure the subsurface resistivity. Table $\mathbf{5}$ shows the summary of total amount of data before and after process.

Table 4 - Resistivity value interpretation based on groundwater in igneous rock [15]

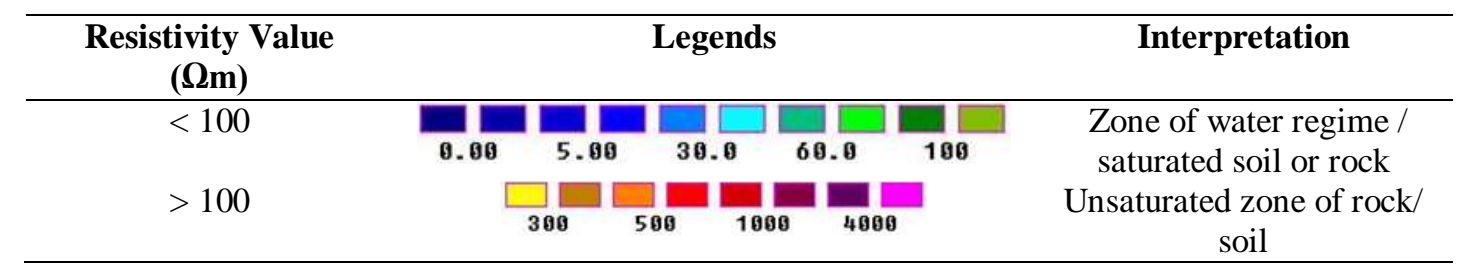

Table 5 - Summary of total amount of data before and after process

\begin{tabular}{ccccccc}
\hline $\begin{array}{c}\text { Profile } \\
\text { Line }\end{array}$ & Protocol & $\begin{array}{c}\text { Number of } \\
\text { Original Data }\end{array}$ & $\begin{array}{c}\text { Negative } \\
\text { Data }\end{array}$ & $\begin{array}{c}\text { Total data } \\
\text { after analysis }\end{array}$ & $\begin{array}{c}\text { “Bad } \\
\text { Data” }\end{array}$ & $\begin{array}{c}\text { RMS } \\
\text { Error }(\%)\end{array}$ \\
\hline (RL1) & Gradient_XL & 925 & 24 & 925 & 0 & 20.9 \\
(RL2) & Gradient_XL & 925 & 20 & 925 & 0 & 18.9 \\
(RL3) & Gradient_XL & 1002 & 45 & 875 & 127 & 25.9 \\
\hline
\end{tabular}

\section{Result and Discussion}

This 2-dimensional electrical resistivity tomography shows the model of subsurface up to 40-meter depth. The type of material is interpreted based on Table 2 and Table 3. The 2-dimensional electrical resistivity tomography plots for line RL1, RL2 and RL3 presented in Fig. 4 indicates that the subsurface profiles have resistivity values range from 5 ohm.m to more than $4000 \mathrm{ohm} . \mathrm{m}$. These highly variable of electrical resistivity values are due to the variable ground water content due to the groundwater pathways. These electrical resistivity tomography profiles are important in assessing the stability of the slope, via focusing to the low resistivity value less than $100 \mathrm{ohm} . \mathrm{m}$ (green and blue) which is interpreted as saturated soil or rock due to groundwater. For survey line RL1, there are unconnected six groundwater pathway zones. In addition, at distance 110 meter to 180 meter shows large and deep groundwater pathway. For survey line RL2, there are five groundwater pathway zones, as well as at distance 105-meter shows large and deep groundwater pathway zones. While at RL3, there are four groundwater pathway zones, however two are connected at 130-meter to 160 -meter. All the survey lines show the groundwater pathway connected with the surface drainage i.e. berm drain.

a

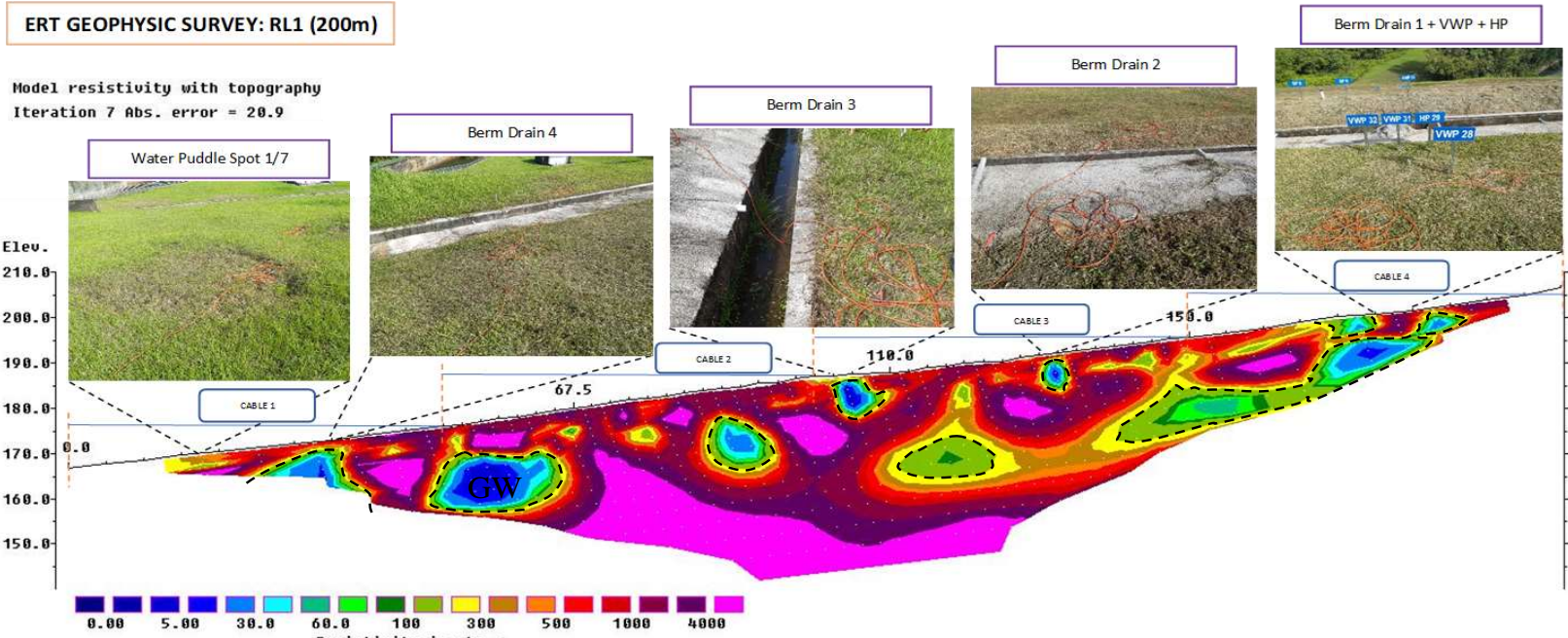


b
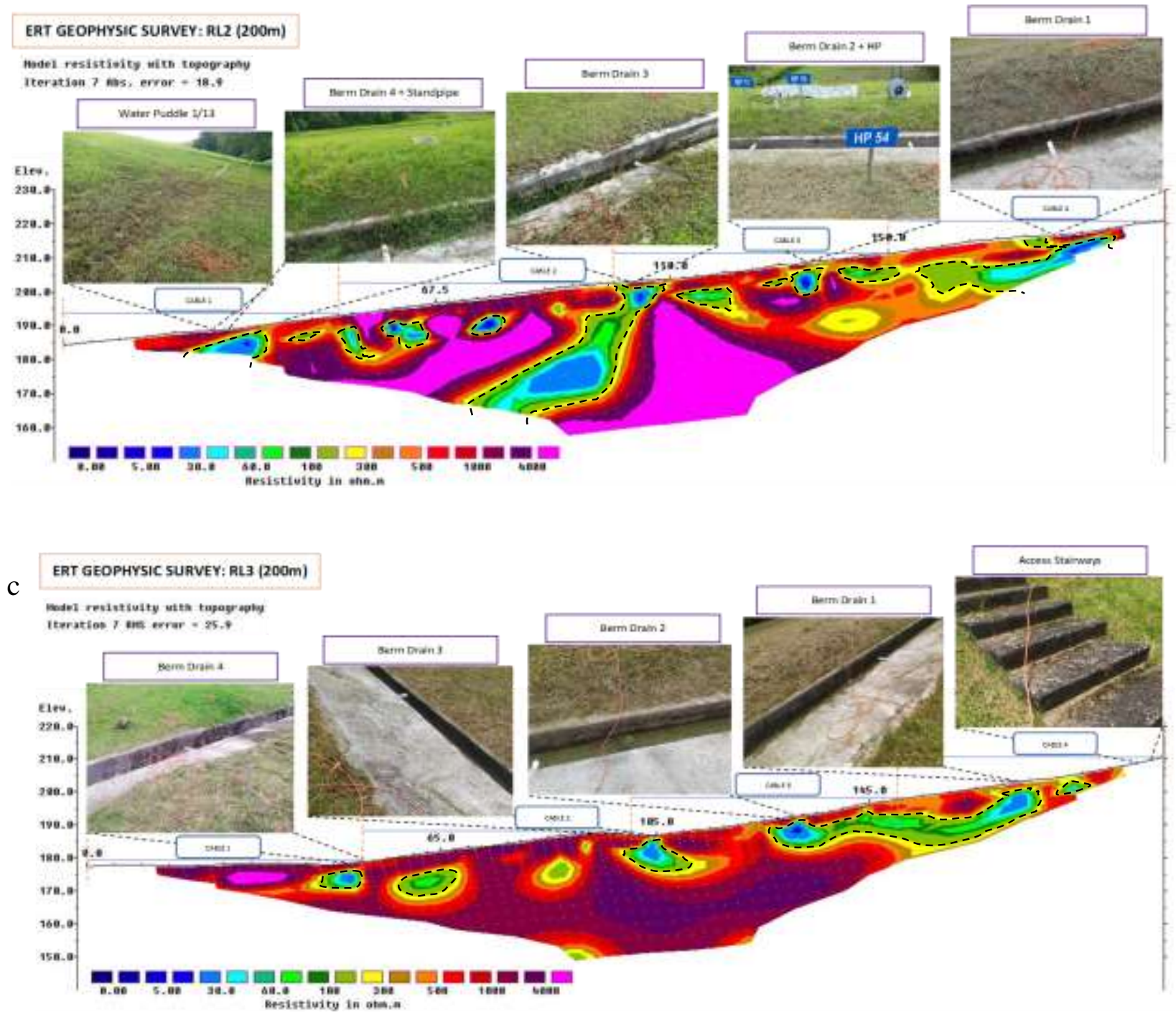

Fig. 4 - The 2-dimensional electrical resistivity tomography models indicating groundwater pathways: (a) resistivity profile for $R L 1$; (b) resistivity profile for $R L 2$; (c) resistivity profile for $R L 3$

\section{Conclusion}

The groundwater pathways within the slope using 2-dimensional electrical resistivity tomography (ERT) are successfully detected. The low resistivity below $100 \mathrm{ohm}-\mathrm{m}$ are indicated as groundwater pathways due to saturated soil or rock. In addition, the slopes indicate that the groundwater pathways are not connected, thus may not affect the global slope stability. This study demonstrates the efficiency of electrical resistivity tomography (ERT) in detecting the groundwater pathways. This investigation will help in sustaining the slope stability via indicating the position of groundwater pathways, and thus implementing the slope remediation work.

\section{Acknowledgement}

The authors would like to thank the Ministry of Higher Education Malaysia for supporting this research under Fundamental Research Grant Scheme Vot No. FRGS/1/2018/STG09/UTHM/02/1 and partially sponsored by Universiti Tun Hussein Onn Malaysia.

\section{References}

[1] Hall, M. R., Lindsay, R. and Krayenhoff, M. (eds) (2012) 'Modern Earth Building', in Modern Earth Buildings. Woodhead Publishing (Woodhead Publishing Series in Energy), pp. 21-25

[2] Arkoprovo, B., Adarsa, J. and Prakash, S. S. (2014) 'Delineation of Groundwater potential zones using Remote Sensing and Geographic Information System Techniques: A case study from Ganjam district, Delineation of 
Groundwater Potential Zones using Satellite Remote Sensing and Geographic Information System', Research Journal of Recent Sciences, 1(9), pp. 59-66

[3] Mohamed, A.-M. O. and Paleologos, E. K. (2018) 'Chapter 5 - Groundwater', in Mohamed, A.-M. O. and Paleologos, E. K. (eds) Fundamentals of Geoenvironmental Engineering. Butterworth-Heinemann, pp. 129-159

[4] Tung, S., Mukherjee, S. and Bhandari, G. (2019) 'Stability of Earthen Embankment with Clay Core Under Tidal Fluctuation', in Lecture Notes in Civil Engineering, pp. 199-207

[5] Morelli, G. and Tayyab, M. H. (2017) 'Investigation of Seepage through Embankment Dam using 3d Investigation of Seepage through Embankmemt Dam in Makkah, Ksa using 3D Electrical Resistivity Tomography and 3D Ground Penetrating Radar Imaging', in Symposium on the Application of Geophysics to Engineering and Environmental Problems 2017, pp. 1-6

[6] Aziman, M., Hazreek, Z. A. M., Azhar, A. T. S., Fahmy, K. A., Faizal, T. B. M., Sabariah, M., Ambak, K. and Ismail, M. A. M. (2018) 'Electrical Resistivity Technique for Groundwater Exploration in Quaternary Deposit', IOP Conf. Series: Journal of Physics: Conf. Series 995, 012110

[7] Hazreek, Z. A. M., Nizam Z. M., Aziman, M., Md Dan, M. F., Shaylinda, M. Z. N., Faizal, T. B. M., Aishah, M. A. N., Ambak, K., Rosli, S., Rais, Y., Ashraf, M. I. M. and Alel, M. N. A. (2018) 'Mapping on Slope Seepage Problem using Electrical Resistivity Imaging (ERI) IOP Conf. Series: Journal of Physics: Conf. Series 995, 012091

[8] Baharuddin, M. F. T., Hazreek, Z. A. M., Azman, M. A. A. and Madun, A. (2018) "Prediction of Groundwater Level at Slope Areas using Electrical Resistivity Method', IOP Conf. Series: Journal of Physics: Conf. Series 995, 012084

[9] Rai, S. N., Kumar, D. and Dubey, K. M. (2013) 'Electrical resistivity tomography for groundwater exploration in a granitic terrain in NGRI campus Electrical resistivity tomography for groundwater exploration in a granitic terrain in NGRI campus', Current Science, 105(11), pp. 1140-1148.Lazzari

[10] Loperte, and Perrone, (2010) 'Advances in Geosciences Near surface geophysics techniques and geomorphological approach to reconstruct the hazard cave map in historical and urban areas', Advances in Geosciences, 24(3), pp. 35-44

[11] Zhu, J., Currens, J. and Dinger, J. (2011) 'Challenges of using electrical resistivity method to locate karst conduits---A field case in the Inner Bluegrass Region, Kentucky', Journal of Applied Geophysics - J APPL GEOPHYS, 75(3), pp. 523-530

[12] Kundu, S. K. (2019) 'Prediction of Settlement of Road Embankment Using Electrical Resistivity Tomography (ERT)', in Urbanization Challenges in Emerging Economies, pp. 639-648

[13] Loke mh (1997) res2dinv ver. 3.3 for windows 3.1, 95, and nt, adv geosci, inc, pp 66

[14] Keller, G.V., and Frischknecht, F.C., (1996). Electrical Method In Geophysics Prospecting. Pergamon Press. Inc., Oxford. p. 517

[15] Zainal Abidin, Madun, A. Tajudin. Ishak (2017) 'Forensic assessment on near surface landslide using electrical resistivity imaging (ERI) AT Kenyir Lake area in Terengganu, Malaysia’, Procedia Engineering, 171, pp. 434444 